This item was submitted to Loughborough's Research Repository by the author.

Items in Figshare are protected by copyright, with all rights reserved, unless otherwise indicated.

\title{
The evolution of Pd/Sn catalytic surfaces in electroless copper deposition
}

\section{PLEASE CITE THE PUBLISHED VERSION}

http://dx.doi.org/10.1149/1.3536543

\section{PUBLISHER}

(C) Electrochemical Society

\section{VERSION}

AM (Accepted Manuscript)

\section{LICENCE}

CC BY-NC-ND 4.0

\section{REPOSITORY RECORD}

Cui, Xiaoyun, David A. Hutt, David J. Scurr, and Paul P. Conway. 2019. "The Evolution of Pd/sn Catalytic Surfaces in Electroless Copper Deposition”. figshare. https://hdl.handle.net/2134/13358. 
This item was submitted to Loughborough's Institutional Repository (https://dspace.lboro.ac.uk/) by the author and is made available under the following Creative Commons Licence conditions.

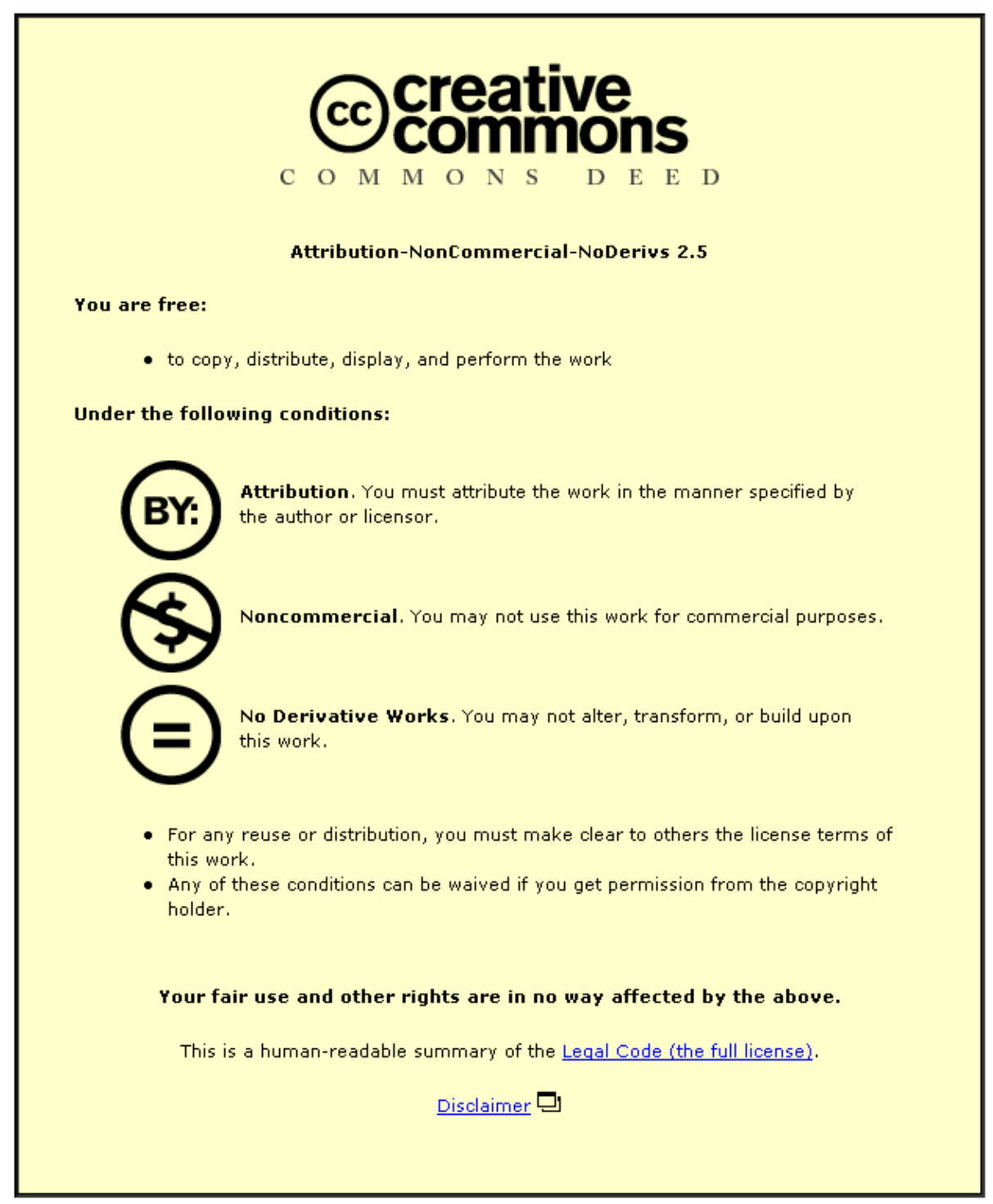

For the full text of this licence, please go to: http://creativecommons.org/licenses/by-nc-nd/2.5/ 


\section{The Evolution of Pd/Sn Catalytic Surfaces in Electroless}

\section{Copper Deposition}

Xiaoyun Cui ${ }^{1 *}$, David. A. Hutt ${ }^{1}$, David. J. Scurr ${ }^{2}$, Paul. P. Conway ${ }^{1}$

1. Wolfson School of Mechanical and Manufacturing Engineering, Loughborough University, Loughborough, LE11 3TU, UK.

2. School of Pharmacy, University of Nottingham, Nottingham, NG7 2RD,UK.

*Corresponding author address: Wolfson School of Mechanical and Manufacturing Engineering, Loughborough University, LE11 3TU, UK E-mail address: $\underline{x . c u i @ l b o r o . a c . u k}$ 


\section{Abstract}

This paper describes the different catalytic surfaces of $\mathrm{Pd} / \mathrm{Sn}$ formed before electroless copper deposition onto a glass substrate. In this study, silanisation of the glass surfaces with (3-aminopropyl) trimethoxysilane was used to provide a surface-coupled layer of functional molecules to assist in the adsorption of $\mathrm{Pd} / \mathrm{Sn}$ catalyst and the subsequent copper deposition. The composition and microstructure of the modified glass surfaces were characterized by X-ray Photoelectron Spectroscopy (XPS) and Time-of-Flight Secondary Ion Mass Spectrometry (ToF-SIMS). These showed that catalytic Pd/Sn structures on the surface changed with increasing immersion time in the catalyst bath. The core level XPS spectrum of Pd indicated that metallic $\operatorname{Pd}(0)$ became more significant in the catalyst layer than Pd(II) with increasing immersion time. A model of the adsorption process is proposed to explain these changes. It was observed that too high a quantity of $\mathrm{Pd}(0)$ does not always improve the adhesion of the $\mathrm{Cu}$ deposits in the electroless process.

Key words: self-assembled monolayer, Pd/Sn catalyst, electroless copper deposition. 


\section{Introduction}

Electroless copper plating is a widely used industrial technique for metallization of insulating substrates such as plastics, glass and ceramics, due to its relatively low cost, established infra-structure and potential for high volume production [1, 2]. Electroless copper is an autocatalytic redox process in which cupric ions $\left(\mathrm{Cu}^{2+}\right)$ are chemically reduced at catalytic surface sites in the absence of any external current source to copper metal $\left(\mathrm{Cu}^{0}\right)[3,4]$. The metallization of glass is of importance due to its use in electronic applications as a substrate material because of its excellent dimensional stability, close match of thermal expansion to silicon and its transparent property. For example, it has been reported that electroless deposition of $\mathrm{Cu}$ on to a glass surface has been investigated for the application of transistor gates for liquid crystal displays [5] and double sided buried contact solar cells [6].

The critical prerequisite for initiating electroless copper deposition on glass substrates is the presence of an appropriate catalytic surface on which to deposit. Glass substrate surfaces are not inherently catalytic and must be activated prior to electroless plating. Pd based catalysts are often used for the electroless metallisation of dielectric materials, and produce a seed layer of palladium on the surface that activates the electroless deposition quickly [7]. A widely used Pd catalyst is based on a 
combination of Sn and Pd chemistry for which there are two main process routes: a two-step process which uses successive dilute solutions of $\mathrm{SnCl}_{2}$ then $\mathrm{PdCl}_{2}[8,9]$; and a one-step process which uses a mixed $\mathrm{SnCl}_{2}-$ $\mathrm{PdCl}_{2}$ colloidal solution $[8,10,11]$. The most extensively used system is the one step, so-called Pd/Sn mixed catalyst (also called PdSn or Pd-Sn). The $\mathrm{Pd} / \mathrm{Sn}$ catalysts are prepared by mixing $\mathrm{PdCl}_{2}$, with a large excess of $\mathrm{SnCl}_{2}$, in $\mathrm{HCl}$ solutions [12]. This produces a solution containing palladium particles surrounded by a tin(IV) shell through the reduction of $\mathrm{Pd}^{2+}$ ions to $\mathrm{Pd}^{0}$ by $\mathrm{SnCl}_{2}$ via the following redox reaction:

$$
\mathrm{Pd}^{2+}+\mathrm{Sn}^{2+} \rightarrow \mathrm{Pd}+\mathrm{Sn}^{4+}
$$

Tin not only acts as the reducing agent for Pd ions, it is also claimed to stabilize the small Pd nuclei once they form via strong $\mathrm{Sn}^{4+}$ adsorption [13]. However, excess ionic tin on the surface of the particles can be detrimental to the electroless plating process. After deposition of the catalyst particles on the surface, the tin shell is usually removed through an acceleration step that exposes the palladium making the catalyst active for initiation of the plating reaction. The acceleration step is often carried out in a separate bath, but if a self-accelerating electroless solution is employed, this separate step is not required as the tin species can be removed in the electroless bath itself [14]. Apart from Pd based catalysts, other noble metal catalysts, such as colloids or nanoparticles of Ag [15] 
and $\mathrm{Au}$ [16], have been used in electroless deposition, but are much less popular.

The technology of Pd/Sn catalysts for electroless deposition has evolved over the years with the aim to achieve uniform catalysis of a range of substrates with good distribution, but it is rare to see detail of research on the $\mathrm{Pd} / \mathrm{Sn}$ catalytic structure evolution on glass substrates. The motivation for the present research was the understanding of the deposition of electroless copper (and nickel) on glass substrates to form conductive tracks and pads for electrical and optical interconnect [14]. Issues were identified with the adhesion between the electroless coating and the smooth glass surface that were found to be dependent on the catalyst treatment conditions and electroless coating thickness. A study of the catalyst deposition on the glass surface was therefore carried out to understand how the surface composition and structure evolves. As the attachment of the $\mathrm{Pd} / \mathrm{Sn}$ to the substrate is also critical, it is usual to apply a pre-treatment to the glass to encourage the adhesion of the catalyst particles to the smooth glass surface $[5,17]$ and in this work, a layer of (3-aminopropyl) trimethoxysilane molecules was used. X-ray photoelectron spectroscopy (XPS), Time-of-Flight Secondary Ion Mass Spectrometry (ToF-SIMS) and Scanning Electron Microscopy (SEM) were used to investigate the chemical and physical changes occurring 
during the various process steps in order to build a picture of the catalyst structure at each stage.

2 Experimental details

\subsection{Materials}

Thin glass sheets $(100 \mu \mathrm{m}$ thick CMZ glass) were used as substrates in this study and obtained from Qioptiq, UK. The glass sheet was sliced into rectangular strips of about $3 \mathrm{~cm} \times 5 \mathrm{~cm}$ in size. (3-aminopropyl) trimethoxysilane (APTS) was purchased from Aldrich. Methanol and Decon 90 were obtained from Fisher Scientific, UK. The series of electroless plating baths, including pre-dip (3340), Pd/Sn catalyst (3344) and formaldehyde-based electroless copper (4750) solution were obtained from Rohm and Haas, UK.

\subsection{Electroless copper process}

The CMZ glass substrate was highly smooth with a surface roughness of less than $1 \mathrm{~nm}$ and surface resistivity around $10^{16} \Omega \mathrm{cm}$. To remove any organic residues and other debris from the surface, glass substrates were cleaned by soaking in a solution of 2.67 vol.\% of Decon 90 in deionized (DI) water for 8 hours. Following this, the sample was rinsed thoroughly in DI water and then immersed for 1 hour in a $5 \times 10^{-3} \mathrm{~mol} / \mathrm{l}$ solution of APTS in a mixture of methanol (95\%) and DI water (5\%). Then the 
samples were rinsed with DI water and dried with a hot air blower. Following this, the glass substrate was dipped in the pre-dip solution for 1 min to prevent drag-in to the catalyst. This was then activated by dipping in the $\mathrm{Pd} / \mathrm{Sn}$ catalyst solution at room temperature $\left(20-24^{\circ} \mathrm{C}\right)$ for periods of time from $30 \mathrm{~s}$ to $8 \mathrm{~min}$ to investigate the influence on the following electroless deposition. After thorough rinsing of the samples with DI water, the glass was transferred to the self-accelerating electroless copper bath with $\mathrm{pH}$ value of 11.5 and operated at $40^{\circ} \mathrm{C}$.

\subsection{Characterization}

\subsubsection{X-Ray Photoelectron Spectroscopy (XPS)}

XPS measurements were carried out using a VG ESCALAB spectrometer equipped with a hemispherical electron analyser and $\mathrm{Al} \mathrm{K \alpha} \mathrm{X}$-ray source (1486.6 eV photons). The X-ray source was run at a power of $160 \mathrm{~W}$ (20 $\mathrm{kV}$ and $8 \mathrm{~mA}$ ). The samples were mounted on the sample stubs by means of double-sided adhesive tape. The core-level spectra were obtained at the photoelectron take-off angle with respect to the sample surface of $90^{\circ}$. The pressure in the analysis chamber was maintained at $5 \times 10^{-7}$ Torr or lower during each measurement. To compensate for surface charging effects, the binding energies (B.E.) were referenced to the C 1 s $(284.9 \mathrm{eV})$ standard and peak positions should therefore be considered as $\pm 0.1 \mathrm{eV}$. 
The hemispherical analyser was operated with the A4 slit and the survey scan spectra shown here were collected from $0 \mathrm{eV}$ to $1100 \mathrm{eV}$ using a pass energy of $85 \mathrm{eV}$ and dwell time of $20 \mathrm{~ms}$, and the core line spectra were recorded using a pass energy of $25 \mathrm{eV}$ and dwell time of $50 \mathrm{~ms}$. Both B.E. values and peak areas of the individual core line spectra were computed by fitting the curves using XPSPEAK41 software, with the full width at half-maximum (FWHM) and Lorentzian-Gaussian ratio of peaks maintained constant for all components in a particular spectrum. Surface atomic ratios were calculated from the peak areas normalised by relative atomic sensitivity factors from survey scans.

\subsubsection{Time-of-Flight Secondary Ion Mass Spectrometry (ToF-SIMS)}

A ToF-SIMS IV instrument (ION-ToF GmbH, Münster, Germany) fitted with a $\mathrm{Bi}^{3+}$ primary ion beam source was used to investigate the surface and operated with a pulsed target current of $\sim 1 \mathrm{pA}$ and an ion beam energy of $25 \mathrm{keV}$. The primary ion source was operated with a pulse width of $19.5 \mathrm{~ns}$ and a repetition rate of $5 \mathrm{kHz}$. Samples were prepared not more than 24 hours before measurement. Negative spectra and positive spectra were acquired on three points with an area of $500 \mu \mathrm{m} \times$ $500 \mu \mathrm{m}$ on every sample, keeping the primary ion dose below $1 \times 10^{12}$ ions $/ \mathrm{cm}^{2}$ in order to ensure the experiment was run within the static limit. 


\subsubsection{Scanning Electron Microscopy (SEM)}

A LEO 1530 VP Field Emission Gun SEM operated at $5 \mathrm{kV}$ and $30 \mathrm{pA}$ was used to aid in qualitative analysis of surface microstructure and morphology.

\section{Results and discussion}

\subsection{Glass Activation Using a Self-assembled Monolayer}

The glass surface was initially cleaned and then immersed in the APTS solution to form a self-assembled monolayer (SAM). The APTS molecules $\left(\mathrm{NH}_{2}-\left(\mathrm{CH}_{2}\right)_{3}-\mathrm{Si}\left(\mathrm{OCH}_{3}\right)_{3}\right)$ consist of a head group $\left(-\mathrm{Si}\left(\mathrm{OCH}_{3}\right)_{3}\right)$ which is expected to couple to the glass surface, enabling the methylene chains $\left(-\left(\mathrm{CH}_{2}\right)_{3}-\right)$ to pack together, thereby exposing the tail group $\left(-\mathrm{NH}_{2}\right)$ at the surface. It is these tail group species that are intended to interact with the $\mathrm{Pd} / \mathrm{Sn}$ catalyst particles [18]. The surface composition was investigated using XPS in order to understand the interaction between the glass substrates and the APTS molecules that were used to form the SAM. Figure 1 shows XPS survey scans of the Decon 90 cleaned glass surface and the glass surface after immersion in APTS solution for 1 hour. The main elements present on both of the surfaces were $\mathrm{Na}, \mathrm{O}, \mathrm{Si}$ and C. The O 1s, Si 2s, and Si 2p signals originate primarily from the glass and to a lesser extent from the grafted silane. The $\mathrm{Na}$ is also partly attributed to the glass composition, but also to adsorbed Na ions from the 
cleaning process. A $\mathrm{N}$ peak appeared in the spectrum of the APTSmodified surface originating from the amine group of the APTS molecules indicating their coupling to the glass surface and the formation of a SAM. This is further supported by the decreasing of the Na signal due to displacement of adsorbed ions and coverage of the glass surface by the silane which attenuates the photoelectron emission from the Na within the glass itself. Meanwhile, the high resolution peak for Si 2p, shown enlarged in the inset of the figures, shows the change in shape following APTS activation. This peak includes both the $2 \mathrm{p}_{1 / 2}$ and $2 \mathrm{p}_{3 / 2}$ components, but these are too close together to be resolved by the instrument and have therefore been treated here as a single peak. For the cleaned surface, only a single peak is present characteristic of $\mathrm{SiO}_{2}$ in the bulk glass, while with APTS, a second smaller peak shifted by $0.5 \mathrm{eV}$ can also be fitted indicative of the different bonding environment of the $\mathrm{Si}$ within the grafted silane.

\subsection{Pd/Sn catalytic surface}

After pre-treatment in the APTS solution for 1 hour, rinsing and immersion in the pre-dip solution for $1 \mathrm{~min}$, the glass was exposed to the catalyst solution. Figure 2 shows a survey scan of the glass surface after 2 min immersion in the catalyst solution. XPS readily detected Pd 3d (325$345 \mathrm{eV})$, Sn 3d (475-497 eV), Sn 3p $\mathrm{p}_{3 / 2}(710-720 \mathrm{eV})$ and Sn 3p $\mathrm{p}_{1 / 2}(750-$ 
$765 \mathrm{eV}$ ) peaks owing to the high sensitivity of this technique to these elements and their position at the surface of the sample. Meanwhile, $\mathrm{O} 1 \mathrm{~s}$, C 1s and Si were also easily detected, but the $\mathrm{N}$ 1s could no longer be easily seen, presumably due to coverage by the $\mathrm{Pd} / \mathrm{Sn}$, but with a closer inspection could be identified as a weak feature as shown in the inset.

In order to investigate the influence of the catalyst solution immersion time on the surface composition, the glass was activated for different periods of time. Figure 3 presents the core level scans of Pd 3d and Sn 3d XPS spectra of the activated substrate for different immersion time in the catalyst solution. The spectra were fitted with a Shirley background and d type peaks within XPSPEAK41.

The Pd spectra present a doublet corresponding to $\mathrm{Pd} 3 \mathrm{~d}_{5 / 2}$ and $\mathrm{Pd} 3 \mathrm{~d}_{3 / 2}$ with a binding energy difference of about $5.3 \mathrm{eV}$ as suggested by [11, 19]. The Pd spectra for $30 \mathrm{~s}$ and 2 min (a and b) could be fitted with two spinorbit-split doublets with the first peak located at $335.4 \mathrm{eV}$ and the second peak located at $337.5 \mathrm{eV}$, while Pd spectrum (c) only presented one doublet with the main peak at $335.4 \mathrm{eV}$. The doublet with the Pd $3 \mathrm{~d}_{5 / 2}$ peak in $(\mathrm{a}, \mathrm{b})$ lying at $337.5 \mathrm{eV}$ is attributed to $\mathrm{Pd}(\mathrm{II})$ and the other peak at $335.4 \mathrm{eV}$ is attributed to $\operatorname{Pd}(0)$ [11]. It was seen that $\operatorname{Pd}(0)$ became more significant in the catalytic layer than $\mathrm{Pd}(\mathrm{II})$ with increasing 
immersion time from $0.5 \mathrm{~min}$ to $2 \mathrm{~min}$. All the Pd(II) was transferred to Pd(0) after 8 min immersion in the catalyst solution. The Pd(II) peak, located at $337.5 \mathrm{eV}$, is thought to be due to some $\mathrm{PdCl}_{2}$ from the solution [11] or Pd-N bonding [18].

The corresponding Sn 3d XPS spectra, shown on the right side of Figure 3, present doublets of $\mathrm{Sn} 3 \mathrm{~d}_{5 / 2}$ and $\mathrm{Sn} 3 \mathrm{~d}_{3 / 2}$ peaks with $8.5 \mathrm{eV}$ binding energy difference. Sn spectra could be fitted with two spin-orbit split doublets. The main $\mathrm{Sn} 3 \mathrm{~d}_{5 / 2}$ doublet peak at 486.5 to $486.4 \mathrm{eV}$ can be attributed to $\mathrm{Sn}(\mathrm{II})$ or $\mathrm{Sn}(\mathrm{IV})$, which are difficult to assign due to their similar binding energy values [9]; however, considering the catalyst mechanism, it was thought to be mostly Sn(IV). The weak doublet where the $\mathrm{Sn} 3 \mathrm{~d}_{5 / 2}$ peak lies at $484.6 \mathrm{eV}$ is thought to be representative of metallic tin, $\operatorname{Sn}(0)$.

Table 1 lists the elemental ratios obtained from the areas of the XPS spectra from the high resolution scans, which allow the determination of the relative quantity of Pd and Sn when the substrate was immersed for different time in solution. The increasing immersion time in the catalyst induced a small increase in the Sn metallic state compared to the Sn(IV), but a much more obvious increase in the total adsorbed Sn was observed. The ratio of Sn/Pd increased with increasing immersion time, as did the 
amount of Pd metallic form compared to the Pd(II) state. The presence of $\operatorname{Sn}(0)$ implies that the core of the catalyst colloid particles contain some Pd-Sn metallic alloy, in agreement with other studies [11, 20] due to the following reaction:

$$
2 \mathrm{Sn}^{2+} \rightarrow \mathrm{Sn}+\mathrm{Sn}^{4+}
$$

Figure 4 shows the corresponding surface morphology of the glass surface after different immersion time in the catalyst solution. Some clumps of particles could be seen as white patches in the images and appeared to be due to nanoparticle agglomerates. The amount of the adsorbed catalyst particles increased as the immersion time increased, leading to a uniform distribution of catalytic particles.

Positive and negative secondary ion SIMS spectra were obtained from the glass surface subjected to immersion in the catalyst solution for different periods of time. Figure 5 shows the spectra from the sample immersed for $2 \mathrm{~min}$. In the positive spectrum a number of peaks at $\mathrm{m} / \mathrm{z}<100$ were identified and corresponded to the hydrocarbon fragments $\mathrm{C}_{\mathrm{y}} \mathrm{H}_{\mathrm{x}}$, as shown in Figure 5a. It was noticed that $\mathrm{CH}_{2} \mathrm{NH}_{2}{ }^{+}$and $\mathrm{CH}_{2} \mathrm{CH}_{2} \mathrm{NH}_{2}{ }^{+}$were also detected at $\mathrm{m} / \mathrm{z}=30$ and 44 respectively. Above $\mathrm{m} / \mathrm{z}>100$, peaks at $\mathrm{m} / \mathrm{z}$ 104, 105, 106, 108 and 110 as well as $\mathrm{m} / \mathrm{z}=116,117,118,119,120$, 122 and 124 were identified corresponding to $\mathrm{Pd}^{+}$and $\mathrm{Sn}^{+}$respectively, according to the standard isotope peaks and corresponding abundances of 
the isotope database [21]. Secondary ion peaks were observed at $\mathrm{m} / \mathrm{z}=$ 121, 123 and 125 which have been assigned to ${ }^{106} \mathrm{PdNH}^{+},{ }^{108} \mathrm{PdNH}^{+}$, ${ }^{110} \mathrm{PdNH}^{+}$respectively. No $\mathrm{Sn}^{+}$related peaks are expected at this location. The peaks around $\mathrm{m} / \mathrm{z}=135$ are thought to be due to a combination of $\mathrm{SnNH}^{+}$and $\mathrm{SnOH}^{+}$fragments. The negative spectrum is dominated by high intensity secondary ions from ${ }^{35} \mathrm{Cl}^{-}$and ${ }^{37} \mathrm{Cl}^{-}(\mathrm{m} / \mathrm{z}=35$ and 37 respectively), $\mathrm{SiO}_{2}{ }^{-}(\mathrm{m} / \mathrm{z}=60)$ and $\mathrm{SnO}_{2}{ }^{-}$(isotope distribution at $\mathrm{m} / \mathrm{z}=$ 149, 150, 151, 152 and 153).

More SIMS analysis was carried out on catalytic surfaces with different immersion time, the species appearing on the surface were the same but there were differences in intensity of the peaks. Figure 6 presents the relationship between the intensity change of the $\mathrm{Pd}^{+}(\mathrm{m} / \mathrm{z}=106), \mathrm{Sn}^{+}$ $(\mathrm{m} / \mathrm{z}=120),{ }^{106} \mathrm{PdNH}^{+}(\mathrm{m} / \mathrm{z}=121),{ }^{120} \mathrm{SnNH}^{+} /{ }^{118} \mathrm{SnOH}^{+}$(peak at $\mathrm{m} / \mathrm{z}=$ 135) as a function of catalyst immersion time obtained from the positive ion spectra. The strongest isotope peaks were selected for comparison. The values indicate the relative intensity of peaks. It was noticed that the ${ }^{106} \mathrm{PdNH}^{+}$signal decreased, while the $\mathrm{Pd}^{+}$and the fragments related to Sn increased in intensity with the increasing immersion time. Within the negative ion SIMS, the secondary ion fragments due to $\mathrm{SnO}_{2}{ }^{-}$also increased greatly with extended immersion time in the catalyst. 
The observation of $\mathrm{SnNH}^{+}$and $\mathrm{PdNH}^{+}$fragments in the SIMS results indicates that the exposed tail group $\left(-\mathrm{NH}_{2}\right)$ of the SAM surface interacts with both Pd and Sn species. In addition, the SIMS spectra showed that the $\mathrm{Sn}(\mathrm{IV})$ observed in the XPS spectra was most likely present as $\mathrm{SnO}_{2}$, rather than the great amount of $\mathrm{SnCl}_{4}$ that was detected by Shukla et al [9] or $\mathrm{SnCl}_{2}$ and $\mathrm{Sn}(\mathrm{OH})_{2}$ suggested by Nicolas-Debarnot et al [11]. These results are very consistent with the conclusion arrived at by Osaka et al that $\mathrm{SnO}_{2}$ probably occurs as $\mathrm{SnO}_{2} \cdot 2 \mathrm{H}_{2} \mathrm{O}$ forming an $\mathrm{Sn}(\mathrm{OH})_{4}$ colloidal sheath, which is considered to cover the catalytic sites [10].

An intriguing feature of the XPS results was the apparent change in oxidation state of the Pd as a function of immersion time. As the solution had been prepared and stored for many months, changes in the condition of the colloids on the surface occurring over time periods of minutes seemed unlikely. The accepted model of the Pd/Sn colloid particles is of a Pd metallic core surrounded by a shell of $\mathrm{Sn}^{4+}$ ions. The data in Table 1 was further evaluated to determine the ratios of $\mathrm{Pd}(0): \mathrm{Sn}(\mathrm{IV})$. For example, if the ratio of $\mathrm{Pd}(0): \operatorname{Pd}(\mathrm{II})$ is 0.7 (for 30s immersion), then:

$$
P d_{\text {Total }}=P d(0)+P d(I I)=P d(0)+\frac{P d(0)}{0.7}=2.43 P d(0)
$$

and similarly for a $\operatorname{Sn}(0): \operatorname{Sn}(\mathrm{IV})$ ratio of 0.1 :

$S n_{\text {Total }}=1.1 S n(I V)$ 
From the corresponding $S n_{\text {Total }}: P d_{\text {Total }}$ ratio of 4.6 , the ratio of $\operatorname{Pd}(0): \operatorname{Sn}(\mathrm{IV})$ is readily obtained as 0.1 . Applying the same method to the ratios of $\mathrm{Pd}(0): \mathrm{Sn}(\mathrm{IV})$ for 2 and 8 min catalyst immersion it was found that the ratio remained approximately the same, around 0.1 , independent of the catalyst immersion time. This is consistent with the proposed colloid model and indicates that as a function of immersion time, the total number of colloids at the surface increases, but the colloid composition is unchanged i.e. the ratio of $\operatorname{Pd}(0)$ to $\operatorname{Sn}(\mathrm{IV})$ is consistent. As mentioned above, the SIMS data indicated the interaction of Sn and Pd with the $\mathrm{NH}_{2}$ tail groups of the SAMs: based on the conventional colloid model of the Pd surrounded by Sn, the interaction of Sn with this surface is anticipated, but Pd is not.

A model of the $\mathrm{Pd} / \mathrm{Sn}$ catalyst structure on the surface as a function of time is therefore proposed as shown in Figure 7. This consists of the conventional view of colloid particles with a core of metallic Pd (with a little metallic Sn as mentioned above, not shown here) with a consistent amount of Sn(IV) in the shell, adsorbing on the surface. However, the coverage of these colloids varies with immersion time such that at short times (e.g. $30 \mathrm{sec}$ ), the coating is incomplete. The remaining surface is exposed to the catalyst solution and becomes coated with free ions of Pd(II) (and Sn(II) and/or Sn(IV)). This structure is expected to show both 
$\mathrm{Pd}(0)$ and $\mathrm{Pd}(\mathrm{II})$ in XPS as observed and also $\mathrm{PdNH}^{+}, \mathrm{SnOH}^{+}$and $\mathrm{SnNH}^{+}$ in SIMS analysis. When the catalyst immersion time increases to 2 min, the ions are displaced (or covered) on the surface by colloid particles so that in XPS the $\operatorname{Pd}(0)$ state increases, while there is still some $\mathrm{Pd}(\mathrm{II})$ and a high concentration of Sn(IV) which corresponds to the higher coverage of catalyst particles. The surface is fully covered with $\operatorname{Pd}(0)$ catalyst particles after 8 min treatment: this structure is likely to show only $\operatorname{Pd}(0)$ and $\mathrm{Sn}(\mathrm{IV})$ in XPS, as found in the results, due to either complete displacement of the $\mathrm{Pd}^{2+}$ ions or attenuation of their signal by the overlying thick layer of colloids. The positive SIMS results showed $\mathrm{SnNH}^{+} / \mathrm{SnOH}^{+}$increased greatly while the $\mathrm{PdNH}^{+}$decreased with increasing immersion time, in agreement with the proposed model.

\subsection{Electroless Copper Deposition}

As described above, the electroless copper solution to be used was a selfaccelerated bath and was therefore expected to strip away the Sn(IV) coating on the catalyst particles to reveal the Pd core before copper plating. To investigate how this would affect the catalysed sample, specimens were pre-treated with APTS solution for 1 hour, pre-dip for 1 min and catalyst for 2 min, then immersed in the electroless plating bath for short periods of time and finally rinsed with DI water and dried. XPS spectra were recorded as shown in Figure 8a and 8b. After 15 sec 
immersion in the electroless copper bath, there was no copper visible in the XPS spectrum and the shape of the Pd spectrum was very similar to that of the catalyst treated surface shown in Figure 3b with two spin-orbit split doublets. The Pd signal decreased in intensity, relative to the catalysed surface, but the Sn signal decreased sharply compared to the value before plating such that the $\mathrm{Sn} / \mathrm{Pd}$ ratio became 0.7 , consistent with the accelerating property of the bath that preferentially dissolves the outer Sn(IV) layer. The spectra of Sn after 15 sec in the electroless $\mathrm{Cu}$ bath could be fitted with one spin-orbit-split doublet located at $486.5 \mathrm{eV}$ which is attributed to $\mathrm{Sn}(\mathrm{IV})$ and one strong peak lying at $497.4 \mathrm{eV}$. The peak at $497.4 \mathrm{eV}$ is thought to be a sodium Auger peak presumably due to some contamination from the electroless copper bath. With increasing immersion time in the electroless Cu bath to 1 min as shown in Figure 8b, there was only some metallic $\operatorname{Pd}(0)$ left, and the Sn signal was very hard to see within the background noise. The presence of some remaining Sn(IV) on the surface is consistent with the model of catalyst acceleration presented by Zabetakis et.al. [7].

Following the previous activation steps, the catalytic samples were immersed into the electroless copper bath for $5 \mathrm{~min}$. An electroless copper film was successfully deposited on the glass surfaces for each of the three catalyst immersion times. However, it was found that the 
adhesion of the copper coating varied according to catalyst treatment time. Using tape peel testing it was observed that the 2 min catalyst treatment offered the best adhesion, although this was limited, as when the thickness of the coating increased above $230 \mathrm{~nm}$ it could still be easily peeled away. This observation can be considered in terms of the model, presented in Figure 7: for short period (30 sec) catalyst treatment, the coverage of catalyst particles was not sufficient so that $\mathrm{Cu}$ particles were not able to adhere across all areas, providing limited points of contact resulting in poor adhesion. It might be expected that the 8 min catalyst treated surface would be more suitable to copper deposition, due to greater coverage of catalyst particles. However, for a long time catalyst treatment, the higher concentration of Pd is thought to result in more rapid reaction in the initial period in the electroless $\mathrm{Cu}$ bath leading to high levels of hydrogen bubbles and internal coating stress. Another possible reason is that with excess catalyst present, the Sn coating on the particles could not be as effectively removed before $\mathrm{Cu}$ plating started.

\section{Conclusion}

The catalytic surface composition plays an important role in electroless deposition on a glass substrate. The evolution of the catalyst structure on the surface of APTS coated glass as a function of immersion time was investigated by XPS and ToF-SIMS. These results indicated a change in 
the composition and surface coverage of the Pd and Sn species with time and a model was developed to explain the observed results. It is thought that for short exposure times that the surface is only partially covered with catalyst particles and that the remaining area has adsorbed Pd and Sn ions attached thereby giving XPS peaks for $\mathrm{Pd}(0)$ and $\mathrm{Pd}(\mathrm{II})$ species. With increasing immersion time, these adsorbed ions are displaced / covered over by additional catalyst particles, such that they are no longer detectable in XPS and the Pd spectra show only peaks due to $\operatorname{Pd}(0)$. The effect of catalyst immersion time on the electroless $\mathrm{Cu}$ deposition was also investigated and it was found that a catalytic surface with an excess or small number of activation sites was not beneficial for electroless $\mathrm{Cu}$ deposits with good surface morphology and adhesion. A surface covered with a more uniform layer of catalyst particles gave the best adhesion of the Cu coating, but was still limited by the thickness of copper deposited.

\section{Acknowledgements}

The authors wish to thank the EPSRC for financial support through the Innovative Electronics Manufacturing Research Centre. The technical support of Qioptiq is also gratefully acknowledged. 


\section{Reference}

1. V. M. Dubin, Y. Shacham-Diamand, B. Zhao and P. K. Vasudev, J. Electrochem. Soc., 144, 898 (1997).

2. G. O. Mallory and J. B. Hajdu, Electroless plating: Fundamentals and Applications, Noyes Publications/William Andrew Publishing, New York (1990).

3. M. Matsuoka, J. Murai and C. Iwakura, J. Electrochem. Soc., 139, 2466 (1992).

4. K. G. Mishra and R. K. Paramguru, J. Electrochem. Soc., 143, 510 (1996).

5. E. Delamarche, J. Vichiconti, S.A. Hall, M. Geissler, W. Graham, B. Michel and R. Nunes, Langmuir, 19, 6567 (2003).

6. J. H. Guo and J. E. Cotter, Sol. Energy Mater. Sol. Cells, 86, 485 (2005).

7. D. Zabetakis and W. J. Dressick, ACS Appl. Mat. Interfaces, 1, 4 (2009).

8. M. Charbonnier, Y. Goepfert, M. Romand and D. Leonard, J. Adhes., 80, 1103 (2004).

9. S. Shukla, S. Seal, J. Akesson, R. Oder, R. Carter and Z. Rahman, Appl. Surf. Sci., 181, 35 (2001).

10. T. Osaka, H. Takamatsu and K. Nihei, J. Electrochem. Soc., 127, $1021(1980)$. 
11. D. Nicolas-Debarnot, M. Pascu, C. Vasile and F. Poncin-Epaillard, Surf. Coat. Technol., 200, 4257 (2006).

12. E. J. M. O'Sullivan, J. Horkans, J. R. White and J. M. Roldan, IBM J. Res. Develop., 32, 591 (1988).

13. R. L. Cohen and K. W. West, J. Electrochem. Soc., 120, 502 (1973).

14. X. Y. Cui, D. Bhatt, D. A. Hutt, K. Williams and P.P. Conway, in manufacturing process, K. Vaidyanathan, T. Y. Tee, and T. K. Lee, Editors, p. 37, Electronics Packaging Technology Conference Proceedings, Singapore (2007).

15. Z. C. Liu, Q. G. He, P. Hou, P. F. Xiao, N. Y. He and Z. H. Lu, Colloids Surf., A, 257-258, 283 (2005).

16. Y. -h. Zhang, T. -t. Yan, S. -q. Yu and S. -y. Zhuang, J. Electrochem. Soc., 146, 1270 (1999).

17. E. Delamarche, M. Geissler, J. Vichiconti, W. S. Graham, P. A. Andry, J. C. Flake, P. M. Fryer, R. W. Nunes, B. Michel, E. J. O'Sullivan, H. Schmid, H. Wolf and R.L. Wisnieff, Langmuir, 19, 5923 (2003).

18. L. Xu, J. Liao, L. Huang, D. Ou, Z. Guo, H. Zhang, C. Ge, N. Gu and J. Liu, Thin Solid Films, 434, 121 (2003).

19. J. F. Moulder, W. F. Stickle, P. E. Sobot and K. D. Bomben, Handbook of X-ray Photoelectron Spectroscopy, Physical Electronics Inc, New York (1995). 
20. M. Froment, E. Queau, J. R. Martin and G. Stremsdoerfer, J. Electrochem. Soc., 142, 3373 (1995).

21. Isotope peak, I.v.s.i. ToF-SIMS, Editor, ION-ToF GmbH, Münster, Germany. 
Figure captions:

Figure 1: XPS survey scans of (a) the cleaned glass surface; and (b) the glass surface after immersion in APTS solution for 1 hour. Insets, show the respective high resolution scans of the Si 2p peak.

Figure 2: XPS survey scan of the glass surface after 2 min immersion in the catalyst solution. Inset shows the $\mathrm{N}$ 1s region enlarged.

Figure 3: Pd 3d and Sn 3d XPS core-level spectra of the activated substrate for (a) $30 \mathrm{sec}$, (b) $2 \mathrm{~min}$, (c) 8 min exposure to the catalyst solution.

Figure 4: SEM images of the catalytic surface with different immersion time (a) $30 \mathrm{sec}$, (b) $2 \mathrm{~min}$, (c) 8 min in the catalyst solution

Figure 5: SIMS spectra of glass surfaces immersed in catalyst solution for 2 min: (a) positive ion $(\mathrm{m} / \mathrm{z}=20-100)$, (b) positive ion $(\mathrm{m} / \mathrm{z}=100-160)$, (c) negative ion.

Figure 6: The intensity variation of different fragments observed in SIMS spectra as a function of catalyst immersion time.

Figure 7: Schematic diagram of different catalytic surface structures as a function of catalyst solution immersion time.

Figure 8: Pd and Sn XPS core-level spectra following immersion in the electroless Cu bath for (a) $15 \mathrm{sec}$, (b) $1 \mathrm{~min}$. 
Figure 1
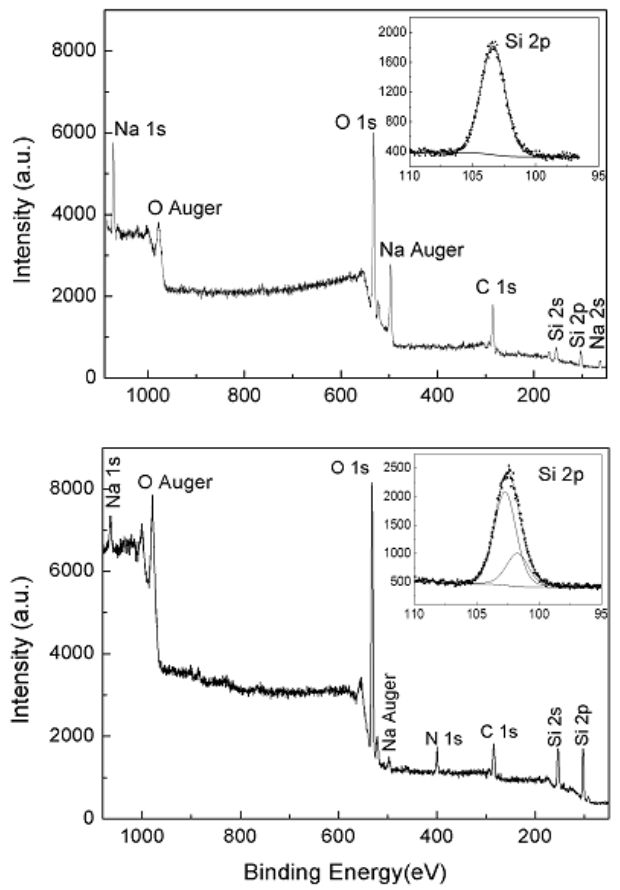
Figure 2

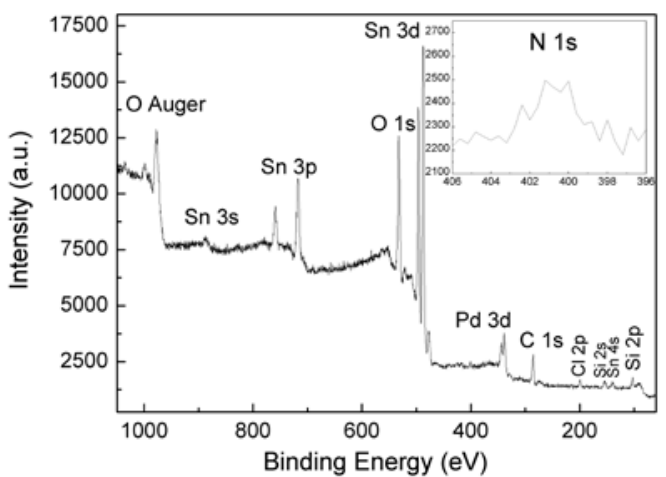


Figure 3
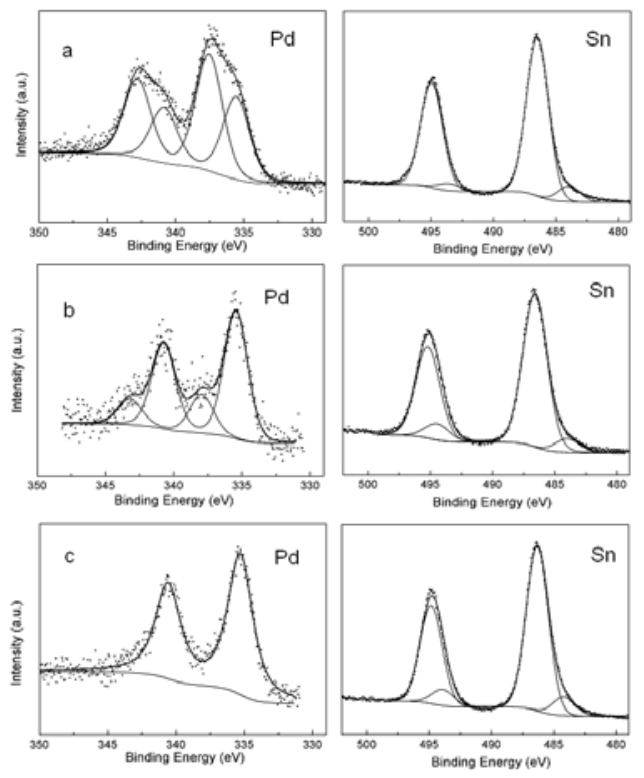
Figure 4

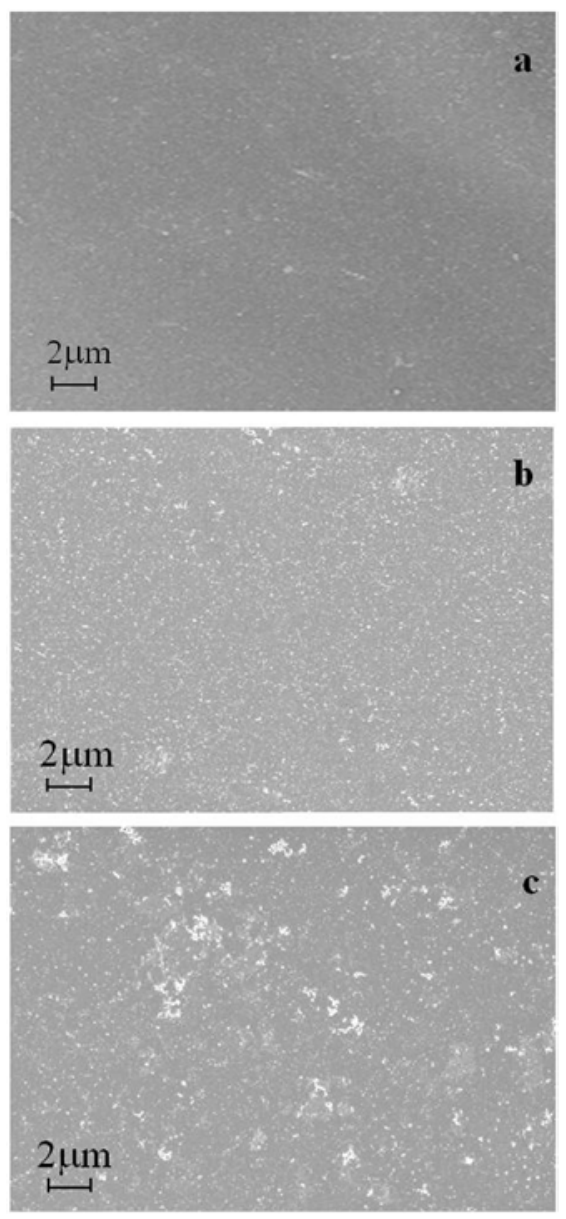


Figure 5

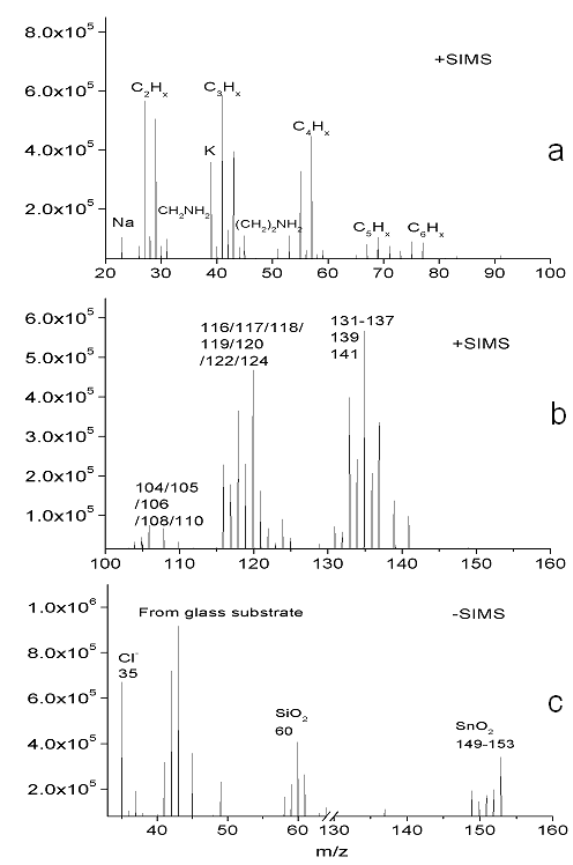


Figure 6

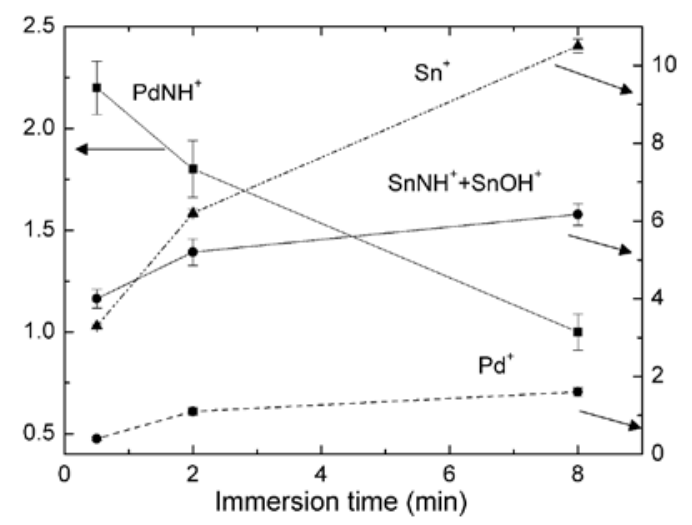




\section{Figure 7}

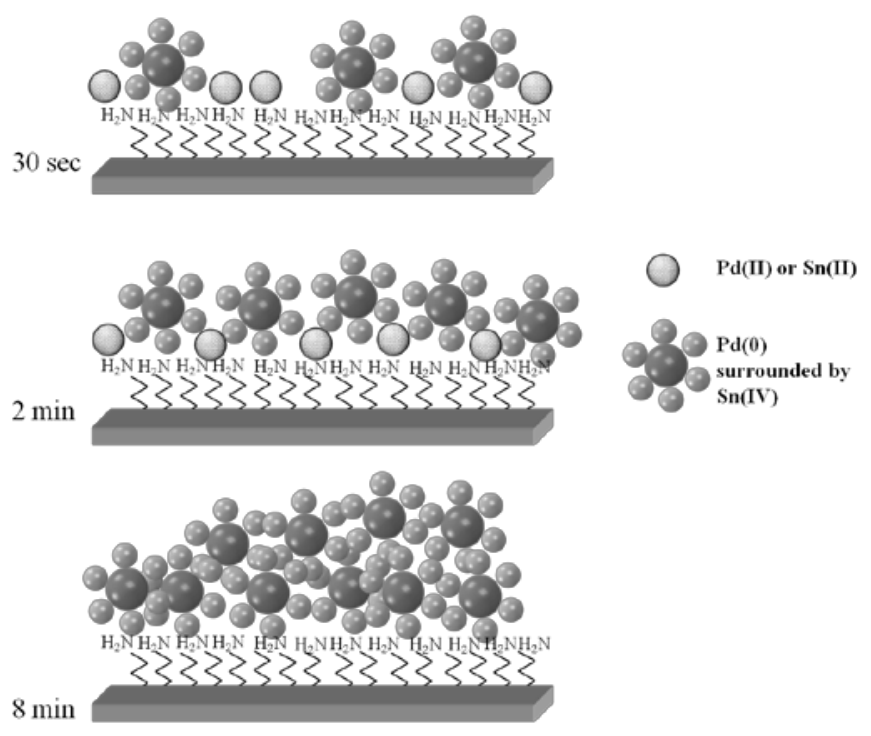


Figure 8
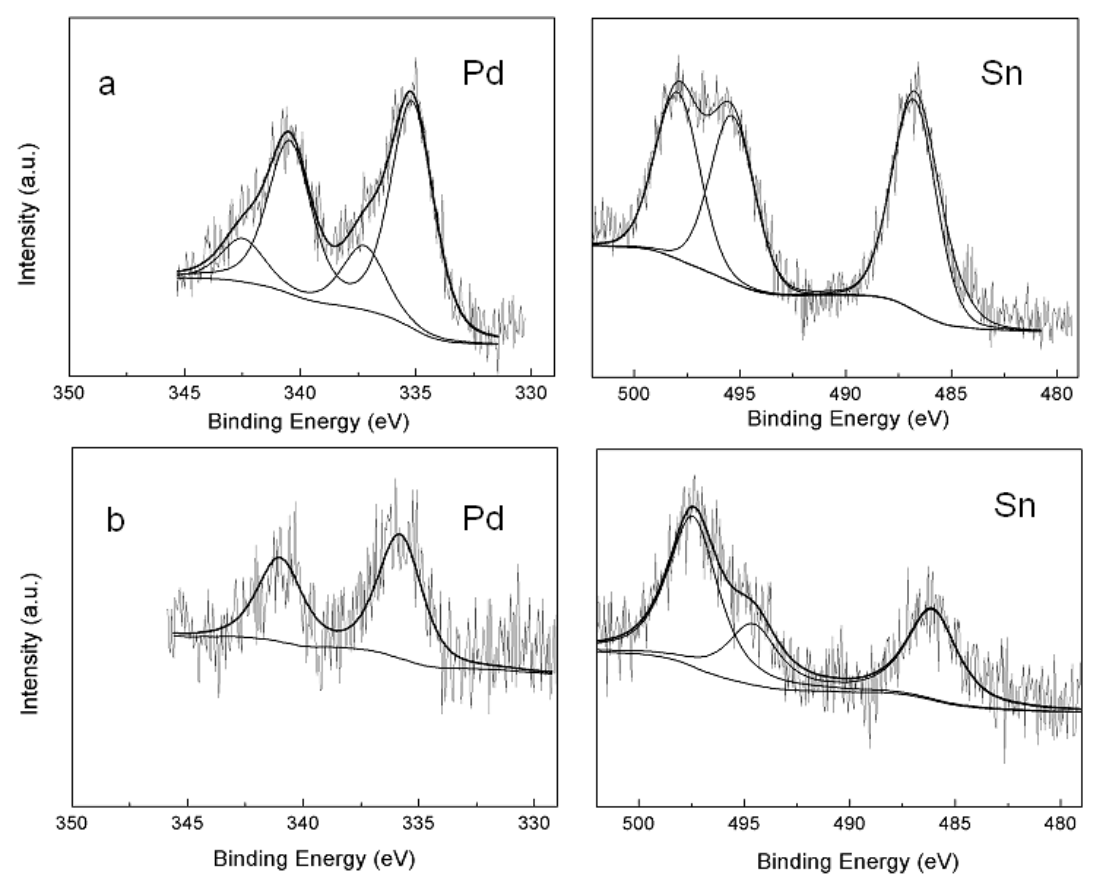
Table caption:

Table 1: Ratios of elemental compositions for different catalyst

immersion times 
Table 1

\begin{tabular}{ccccc}
\hline \hline & Immersion time & $\operatorname{Pd}(0) / \operatorname{Pd}(\mathrm{II})$ & $\mathrm{Sn}(0) / \mathrm{Sn}(\mathrm{IV})$ & $\mathrm{Sn} / \mathrm{Pd}$ \\
\hline \hline a & $30 \mathrm{sec}$ & 0.7 & 0.10 & 4.6 \\
b & 2 min & 3.3 & 0.12 & 8.4 \\
c & 8 min & all Pd(0) & 0.13 & 10.7
\end{tabular}

